\title{
Análise comparativa das propriedades de óxidos transparentes condutores para aplicação em células solares de filmes finos de CdTe
}

\section{Comparative analysis of the properties of transparent conducting oxides for CdTe thin film solar cells}

\author{
Leila Rosa Cruz ${ }^{1}$, Nikolas Branco Padilha ${ }^{2}$, Rodrigo Amaral de Medeiro ${ }^{1}$, \\ Breno Felipe Matos Lopes ${ }^{1}$, Renan de Melo Correia Lima ${ }^{1}$, \\ Carlos Luiz Ferreira ${ }^{1}$, Roberto Ribeiro de Avillez ${ }^{2}$
}

\footnotetext{
${ }^{1}$ Instituto Militar de Engenharia, Seção de Engenharia Mecânica e de Materiais, Praça General Tibúrcio, 80 - Urca, 2290270 - Rio de Janeiro, RJ

e-mail: leilacruz@ime.eb.br; digfisic@gmail.com; breno.felipe.lopes@outlook.com; renanmeloclima@gmail.com; cferreira@ime.eb.br;

${ }^{2}$ Pontifícia Universidade Católica do Rio de Janeiro, Departamento de Engenharia Química e de Materiais, Rua Marquês de São Vicente, 225 - Gávea, 22451-900 - Rio de Janeiro, RJ e-mail: nbpadilha@gmail.com; avillez@puc-rio.br
}

\section{RESUMO}

Este trabalho compara as propriedades de diversos óxidos transparentes condutores para serem utilizados como contatos frontais de células solares de filmes finos de CdTe. Os filmes foram depositados à temperatura ambiente, por pulverização catódica com rádio frequência, sem tratamento térmico posterior, com o objetivo de reduzir o número de etapas do processo de fabricação. A relação resistência/transmitância foi avaliada através de uma figura de mérito, de forma a propor os materiais candidatos a atuar como eletrodo frontal da célula solar. Os óxidos investigados foram divididos em dois grupos: os de baixa resistividade e os de alta resistividade. Eletrodos fabricados com os diversos óxidos foram submetidos a testes de estabilidade térmica nas temperaturas de processamento da célula solar. Os resultados mostraram que os filmes de $\mathrm{ZnO} \mathrm{Zn}_{2} \mathrm{SnO}_{4}$ são óxidos de alta resistividade $\left(>0,5 \Omega\right.$.cm), enquanto que os de $\mathrm{SnO}_{2}, \mathrm{In}_{2} \mathrm{O}_{3}, \mathrm{In}_{2} \mathrm{O}_{3}: \mathrm{Sn}, \mathrm{Cd}_{2} \mathrm{SnO}_{4}$ e $\mathrm{ZnO}: \mathrm{Al}$ são de baixa resistividade $\left(<5,0 \times 10^{-3} \Omega . \mathrm{cm}\right)$ e alta transmitância $(>85 \%)$. Os filmes de $\operatorname{In}_{2} \mathrm{O}_{3}: \mathrm{Sn}$ e $\mathrm{ZnO}: \mathrm{Al}$ apresentaram-se como as melhores opções para fabricação dos eletrodos, pois possuem resistividades na faixa de $10^{-3}-10^{-4} \Omega$.cm e transmitâncias entre $85-92 \%$. No entanto, levando-se em consideração questões de custo e escassez associadas ao índio, filmes de $\mathrm{ZnO}$ :Al são os mais adequados para esta aplicação, pois além de possuírem valores de condutividade e transmitância elevados, apresentaram elevada estabilidade térmica nas temperaturas de processamento da célula.

Palavras-chave: óxidos transparentes condutores; eletrodos transparentes; células solares; filmes finos

\section{ABSTRACT}

This work compares the properties of different transparent conducting oxides for use as frontal contact in CdTe thin films solar cells. The films were deposited at room temperature by radio frequency sputtering without heat treatment, in order to reduce the manufacturing process steps. The resistance/transmittance relation was evaluated using a figure of merit, in order to propose the best material to act as front electrode of the solar cell. The oxides investigated in this work were separated into two groups: low-resistivity and highresistivity oxides. Electrodes were prepared with these oxides and were subjected to thermal stability tests at the elevated temperatures involved in the solar cell processing. The results showed that $\mathrm{ZnO}$ and $\mathrm{Zn}_{2} \mathrm{SnO}_{4}$ films are high-resistivity oxides $(>0,5 \Omega . \mathrm{cm})$, while $\mathrm{SnO}_{2}, \mathrm{In}_{2} \mathrm{O}_{3}, \mathrm{In}_{2} \mathrm{O}_{3}: \mathrm{Sn}, \mathrm{Cd}_{2} \mathrm{SnO}_{4}$, and $\mathrm{ZnO}$ :Al are lowresistivity $\left(<5,0 \times 10^{-3} \Omega . \mathrm{cm}\right)$ and high transmittance $(>85 \%)$ oxides. The $\operatorname{~}_{2} \mathrm{O}_{3}: \mathrm{Sn}$ and $\mathrm{ZnO}$ :Al films were the best options for the production of the electrodes, as their resistivity and transmittance values ranged from 
$10^{-3}-10^{-4} \Omega . \mathrm{cm}$ and $85-92 \%$, respectively. However, taking into consideration the cost and shortage issues, $\mathrm{ZnO}: \mathrm{Al}$ films are the suitable choice for this application, because in addition to having high values of conductivity and transmittance, they have demonstrated thermal stability at elevated temperatures.

Keywords: conducting transparent oxides; transparent electrodes; solar cells; thin films.

\section{INTRODUÇÃO}

Filmes finos de óxidos transparentes e condutores (OTC) são utilizados em diversos dispositivos tais como sensores de gás, transdutores piezoelétricos e dispositivos optoeletrônicos [1]. Em células solares fotovoltaicas, os OTCs atuam como contato elétrico frontal ou, até mesmo, como camada ativa do dispositivo. Nas células cristalinas da Sanyo (células HIT), por exemplo, o óxido de zinco atua como contato frontal e contato de fundo em uma heterojunção bifacial formada por uma lâmina de silício monocristalino e filme fino de silício amorfo hidrogenado [2]. Também nas células de silício amorfo hidrogenado, um OTC é usado como eletrodo de topo [3]. Entre os OTCs, destacam-se o óxido de índio dopado com estanho $\left(\operatorname{In}_{2} \mathrm{O}_{3}\right.$ :Sn), o óxido de estanho dopado com flúor $\left(\mathrm{SnO}_{2}: \mathrm{F}\right)$, o óxido de zinco dopado com o alumínio ( $\left.\mathrm{ZnO}: \mathrm{Al}\right)$ e o estanato de cádmio $\left(\mathrm{Cd}_{2} \mathrm{SnO}_{4}\right)[4,5]$.

A Tabela 1 mostra a resistividade $(\rho)$ e a transmitância média na região visível do espectro eletromagnético $(\mathrm{T})$ de vários OTCs, conforme relatado na literatura [3-8]. Os óxidos $\mathrm{In}_{2} \mathrm{O}_{3}$ e $\mathrm{Zn}_{2} \mathrm{SnO}_{4}$ são chamados de óxidos de alta resistividade (OTC-a), pois possuem resistividades duas a três ordens de grandeza acima dos demais, chamados de baixa resistividade (OTC-b). Apesar da resistividade elevada, os óxidos OTC-a possuem uma aplicação importante em células solares de filmes finos de telureto de cádmio (CdTe), exercendo a função de camada "tampão" isolante. Nestas células, esta camada "tampão" situa-se entre o eletrodo frontal de baixa resistividade (OTC-b) e a janela da célula, a qual é formada por um filme de sulfeto de cádmio (CdS). A configuração originalmente proposta para estas células, vidro/OTC-b/CdS/CdTe, foi modificada para vidro/OTC-b/OTC-a/CdS/CdTe, tal como mostrado na Figura 1, onde o papel da camada "tampão" de OTC-a é reduzir as chances de formação de junções OTC-b/CdTe [7, 9]. Estas junções indesejáveis ocorrem localmente no dispositivo, como resultado de variações na espessura da camada de CdS, que é muito fina (60-80 nm).

Tabela 1: Propriedades elétricas e óticas dos principais OTCs investigados na literatura [3-8].

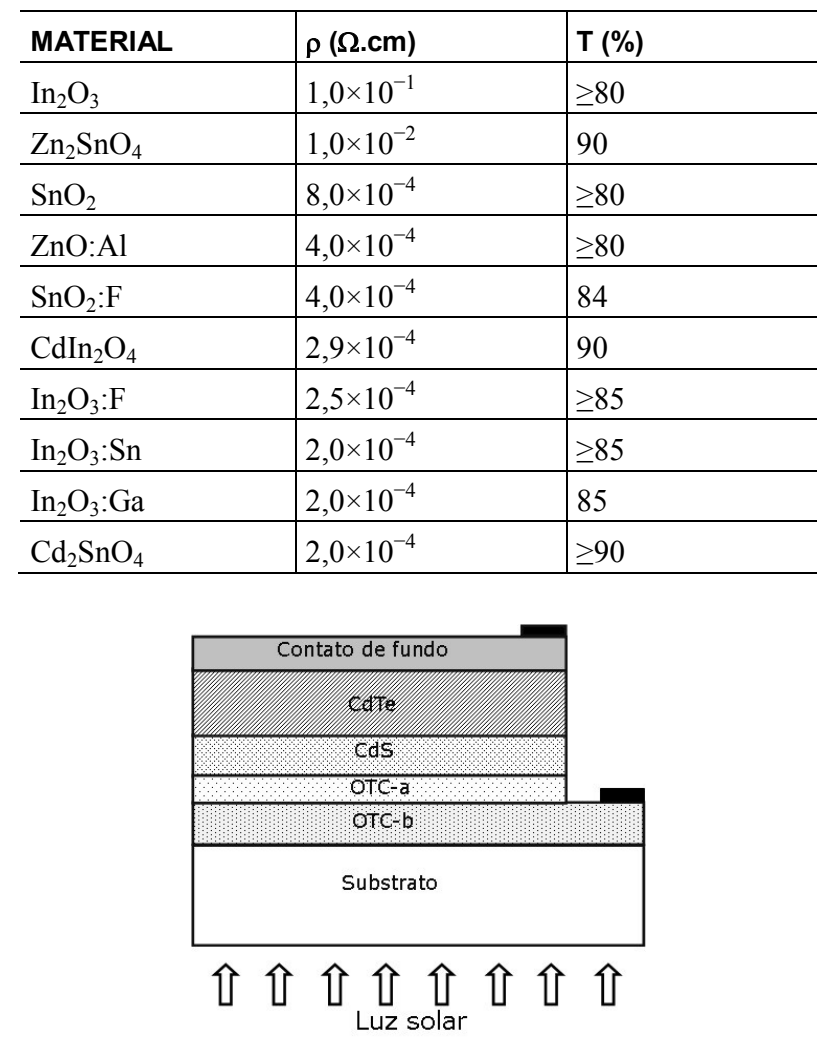

Figura 1: Configuração de uma célula solar de filme fino de CdTe: vidro/OTC-b/OTC-a/CdS/CdTe/contato, conforme proposta de Wu e col [9]. 
No entanto, baixa resistividade e alta transmitância na região visível do espectro são, de fato, as propriedades buscadas quando OTCs são usados como eletrodos frontais de vários dispositivos. Mesmo possuindo estas propriedades, a escolha do material é muitas vezes limitada pelo processamento ao qual o OTC será submetido durante a fabricação do dispositivo. O ZnO:Al, por exemplo, não é tóxico, é abundante na natureza e mais barato que os demais [10]. Além disso, apesar de não possuir uma resistividade tão baixa quanto à do $\mathrm{In}_{2} \mathrm{O}_{3}: \mathrm{Sn}, \mathrm{o} \mathrm{ZnO}: \mathrm{Al}$ é bem estável em atmosfera de hidrogênio $\left(\mathrm{H}_{2}\right)$, o que é particularmente importante durante a fabricação de dispositivos que utilizam plasma de $\mathrm{H}_{2}$ [11]. Já os óxidos de índio-estanho e cádmio são os mais condutores, mas sua escolha envolve questões de escassez e preocupação associada ao uso do cádmio.

A característica comum aos OTCs é o mecanismo de condução elétrica, o qual é controlado pelo desvio da estequiometria. As vacâncias de oxigênio conferem a natureza tipo-n a estes óxidos semicondutores, mas diminuem sua transmitância na região visível do espectro. Para aumentar a condutividade, os OTCs são dopados com elementos que aumentam a concentração de elétrons livres. A relação entre condutividade e transparência está fortemente ligada à microestrutura do filme, a qual, por sua vez, depende do processo e dos parâmetros de deposição [12]. Dentre os processos de deposição de OTCs [4, 5, 10, 11], destaca-se a pulverização catódica com rádio frequência, por permitir melhor controle da estequiometria dos filmes a partir de parâmetros de deposição, tais como, pressão, potência de trabalho e temperatura do substrato. Este último controla a microestrutura dos filmes (tamanho de grão, densidade de vacâncias e dopantes) e, consequentemente, a concentração de elétrons livres e a resistividade. Filmes de baixa resistividade têm sido obtidos sobre substratos aquecidos [11]. No entanto, poucos autores conduzem o processo à temperatura ambiente; geralmente, submetem os filmes a posterior tratamento térmico [13].

No Brasil, vários grupos investigam as propriedades de OTCs depositados por diferentes técnicas, tais como, pirólise com spray [14], evaporação por feixe de elétrons [15] e sol-gel [16], somente para citar algumas. Nestes processos, em geral, altas temperaturas são necessárias durante a deposição do filme ou mesmo após a deposição, via tratamento térmico.

Neste trabalho, vários OTCs foram depositados à temperatura ambiente, por pulverização catódica com rádio frequência, sem tratamento térmico posterior, com o objetivo de reduzir o número de etapas do processo de fabricação. A relação resistência/transmitância foi avaliada através de uma figura de mérito [17], de forma a propor o melhor material para contatos frontais de células solares de filmes finos de CdTe.

\section{MÉTODO EXPERIMENTAL}

Os filmes de OTCs foram crescidos sobre lâminas de vidro soda-lime pela técnica de pulverização catódica com radiofrequência e campo magnético, em um equipamento não comercial, desenvolvido no próprio laboratório [18].

Antes das deposições, foram realizadas purgas de argônio, a fim de garantir uma atmosfera residual inerte. Estabelecidos o plasma, a potência e a taxa de deposição, a deposição sobre os substratos era iniciada acionando-se um anteparo mecânico localizado entre o alvo e o porta-substratos. Este anteparo era novamente acionado ao término da deposição, depois de alcançada a espessura desejada. A taxa de deposição foi monitorada por um sensor de quartzo localizado ao lado dos substratos. Neste sistema, o porta-substratos girava em torno de seu eixo central, de forma a proporcionar maior uniformidade de espessura.

Os filmes foram depositados em condições similares: a pressão base do sistema foi de $2 \times 10^{-6}$ Torr; a pressão de deposição e a distância alvo-substrato foram mantidas em $1 \mathrm{mTorr}$ de argônio e $75 \mathrm{~mm}$, respectivamente. Os substratos foram mantidos à temperatura ambiente, de forma a avaliar a possibilidade de se obter filmes com baixa resistividade e alta transmitância nestas condições. A temperatura dos substratos durante o crescimento dos filmes não ultrapassou o valor de $28{ }^{\circ} \mathrm{C}$. A potência de pulverização foi variada tal como mostrado na Tabela 2, que apresenta os OTCs investigados neste trabalho e as respectivas condições de deposição. Os alvos utilizados foram da AJA International Inc., com 99,999\% de pureza e diâmetro de 3". O tempo de deposição variou, em função da potência, de forma a obter a espessura desejada para cada filme.

A espessura dos filmes foi medida em um perfilômetro da Veeco, modelo Dektak 150. Para a caracterização elétrica utilizou-se um sistema de medidas de efeito Hall, da Bio-Rad, modelo HL 5500, que utiliza o método Van der Pauw. Os espectros de transmitância foram obtidos em um espectrofotômetro da Varian, modelo Cary 5000. 
Tabela 2: Parâmetros de deposição de filmes de OTCs depositados sobre vidro, à temperatura ambiente, por pulverização catódica com rádio frequência $(\mathrm{P}=$ potência; $\mathrm{t}=$ tempo $)$.

\begin{tabular}{l|l|l|l|l}
\hline ALVO & OTC & AMOSTRA & P (W) & $\mathbf{t}(\mathbf{m i n})$ \\
\hline $\mathrm{SnO}_{2}$ & $\mathrm{SnO}_{2}$ & TO-50 & 50 & 39,9 \\
\hline $\mathrm{SnO}_{2}$ & $\mathrm{SnO}_{2}$ & TO-70 & 70 & 24,0 \\
\hline $\mathrm{SnO}_{2}$ & $\mathrm{SnO}_{2}$ & TO-85 & 85 & 18,1 \\
\hline $98 \% \mathrm{ZnO}-2 \% \mathrm{Al}$ & $\mathrm{ZnO}: \mathrm{Al}$ & AZO-90 & 90 & 50,2 \\
\hline $98 \% \mathrm{ZnO}-2 \% \mathrm{Al}$ & $\mathrm{ZnO}: \mathrm{Al}$ & AZO-95 & 95 & 70,2 \\
\hline $\mathrm{In}_{2} \mathrm{O}_{3}$ & $\mathrm{In}_{2} \mathrm{O}_{3}$ & IO-40 & 40 & 37,0 \\
\hline $\mathrm{In}_{2} \mathrm{O}_{3}$ & $\mathrm{In}_{2} \mathrm{O}_{3}$ & IO-55 & 55 & 28,0 \\
\hline $\mathrm{In}_{2} \mathrm{O}_{3}$ & $\mathrm{In}_{2} \mathrm{O}_{3}$ & IO-75 & 75 & 17,1 \\
\hline $90 \% \mathrm{In}_{2} \mathrm{O}_{3}-10 \% \mathrm{SnO}_{2}$ & $\mathrm{In}_{2} \mathrm{O}_{3}: \mathrm{Sn}_{2}$ & ITO-50 & 50 & 30,0 \\
\hline $90 \% \mathrm{In}_{2} \mathrm{O}_{3}-10 \% \mathrm{SnO}_{2}$ & $\mathrm{In}_{2} \mathrm{O}_{3}: \mathrm{Sn}$ & ITO-60 & 60 & 26,0 \\
\hline $\mathrm{Cd}_{2} \mathrm{SnO}_{4}$ & $\mathrm{Cd}_{2} \mathrm{SnO}_{4}$ & CTO-45 & 45 & 35,0 \\
\hline $\mathrm{Cd}_{2} \mathrm{SnO}_{4}$ & $\mathrm{Cd}_{2} \mathrm{SnO}_{4}$ & CTO-60 & 60 & 22,7 \\
\hline $\mathrm{Zn}_{2} \mathrm{SnO}_{4}$ & $\mathrm{Zn}_{2} \mathrm{SnO}_{4}$ & ZTO-60 & 60 & 30,0 \\
\hline $\mathrm{Zn}_{2} \mathrm{SnO}_{4}$ & $\mathrm{Zn}_{2} \mathrm{SnO}_{4}$ & $\mathrm{ZTO-80}$ & 80 & 24,8 \\
\hline $\mathrm{Zn}_{2} \mathrm{SnO}_{4}$ & $\mathrm{Zn}_{2} \mathrm{SnO}_{4}$ & ZTO-100 & 100 & 17,5 \\
\hline $\mathrm{ZnO}$ & $\mathrm{ZnO}$ & $\mathrm{ZO}-95$ & 95 & 47,6 \\
\hline
\end{tabular}

\section{RESULTADOS E DISCUSSÃO}

A Tabela 3 mostra os resultados das caracterizações elétrica e ótica dos filmes depositados. São apresentadas a transmitância (T), a espessura (d), a resistência de folha (Rs) e a resistividade ( $\rho$ ) dos filmes. Os valores de $\mathrm{T}$ situaram-se entre $84-92 \%$ e referem-se à transmitância média dos filmes na faixa da radiação visível entre 450-800nm, já excluída a parcela do substrato. Inicialmente, vale observar que, na faixa de potência investigada, a resistência de folha e a transmitância de filmes com mesma espessura foram pouco afetadas pela potência de pulverização; em geral, um aumento da potência levou a um pequeno decréscimo da resistência. Destaca-se também que a resistividade dos filmes produzidos neste trabalho é similar à relatada na literatura (Tabela 1). A exceção refere-se aos filmes de $\mathrm{In}_{2} \mathrm{O}_{3}$, os quais, neste trabalho, alcançaram valores de resistividade três ordens de grandeza abaixo do valor reportado na Tabela 1. Estudos adicionais são necessários para entender este comportamento, uma vez que o $\operatorname{In}_{2} \mathrm{O}_{3}$, por não ser dopado, deveria ser resistivo. É possível que a estequiometria do alvo tenha sido afetada após várias deposições, de forma que a composição do filme depositado tenha sido bem diferente da estequiométrica. Já os filmes de $\mathrm{ZnO}$ são naturalmente resistivos, conforme esperado, devido à falta de dopagem.

Os OTCs de alta resistividade (OTC-a) mostrados na Tabela 3, tais como o $\mathrm{ZnO}$ e o $\mathrm{Zn}_{2} \mathrm{SnO}_{4}$, podem ser usados como camada "tampão" isolante em células solares de CdTe, pois possuem transmitância e resistividade requeridas para tal aplicação [9]. Os demais filmes podem ser classificados como de baixa resistividade (OTC-b) e, para fazer uma análise comparativa de seu desempenho como eletrodo transparente, pode-se fazer uso do parâmetro $\phi$, também apresentado na Tabela 3. Este parâmetro é uma figura de mérito especificamente definida para OTCs, que otimiza a relação transmitância/resistência de acordo com a Equação 1 [17]. Alta transmitância e baixa resistência são os requisitos fundamentais para OTCs serem usados como contatos frontais em células solares. Ocorre que, quanto mais transparente for o óxido, maior será sua resistência. Esta figura de mérito é então definida de tal forma que, quanto maior for o seu valor, melhor será o compromisso entre alta transmitância e baixa resistência. Os dados mostram que os filmes de $\operatorname{In}_{2} \mathrm{O}_{3}, \mathrm{In}_{2} \mathrm{O}_{3}: \mathrm{Sn}$ e $\mathrm{ZnO}: \mathrm{Al}$ apresentaram os maiores valores de $\phi$, o que os classificaria como os mais indicados para fabricação dos eletrodos frontais do dispositivo.

$$
\Phi=\frac{T^{10}}{R s}
$$

Para serem utilizados como eletrodos frontais em células solares de CdTe, no entanto, os OTCs devem também ser estáveis nas temperaturas de crescimento das demais camadas do dispositivo. Os filmes de $\operatorname{In}_{2} \mathrm{O}_{3}$, $\mathrm{In}_{2} \mathrm{O}_{3}: \mathrm{Sn}$ e $\mathrm{ZnO}: \mathrm{Al}$ foram então submetidos às condições de crescimento da célula de configuração vidro/OTC-b/CdS/CdTe, quais sejam: pressão residual de argônio $=2$ Torr; temperatura $=450^{\circ} \mathrm{C}$. Os filmes de $\mathrm{In}_{2} \mathrm{O}_{3}$ tornaram-se altamente resistivos, com Rs alcançando valores em torno de $300 \Omega / \mathrm{qd}$, o que mostra sua 
instabilidade térmica nesta temperatura. Este resultado era esperado, uma vez que estes filmes não são dopados. Assim, sua condutividade elétrica é controlada unicamente pelas vacâncias de oxigênio, as quais foram preenchidas durante o processamento do filme de CdS. Estes filmes seriam então os mais indicados para dispositivos cujo processamento não envolvesse altas temperaturas. Os outros candidatos a OTC de baixa resistividade, $\mathrm{In}_{2} \mathrm{O}_{3}$ :Sn e o $\mathrm{ZnO}: \mathrm{Al}$, com resistividades da ordem de $10^{-3}-10^{-4} \Omega . \mathrm{cm}$, mostraram boa estabilidade térmica a $450^{\circ} \mathrm{C}$. Assim, estes filmes são uma excelente alternativa para fabricação dos eletrodos frontais das células solares de filmes finos de CdTe.

Tabela 3: Propriedades elétricas e óticas de filmes de OTCs depositados sobre vidro, à temperatura ambiente, por pulverização catódica com rádio frequência.

\begin{tabular}{l|l|l|l|l|l|l}
\hline OTC & AMOSTRA & $\mathbf{d}(\mathbf{n m})$ & $\mathbf{R s}(\mathbf{\Omega} / \mathbf{q d})$ & $\boldsymbol{\rho}(\mathbf{\Omega} \cdot \mathbf{c m})$ & $\mathbf{T}^{*}(\mathbf{\%})$ & $\mathbf{\Phi}\left(\mathbf{1 0 ^ { - 3 } \mathbf { \Omega } ^ { - 1 } )}\right.$ \\
\hline $\mathrm{SnO}_{2}$ & TO-50 & 156 & 198,7 & $3,1 \times 10^{-3}$ & 87 & 1,3 \\
\hline $\mathrm{SnO}_{2}$ & TO-70 & 152 & 190,8 & $2,9 \times 10^{-3}$ & 85 & 1,0 \\
\hline $\mathrm{SnO}_{2}$ & TO-85 & 156 & 179,5 & $2,8 \times 10^{-3}$ & 85 & 1,1 \\
\hline $\mathrm{ZnO}: \mathrm{Al}$ & AZO-90 & 216 & 39,8 & $8,6 \times 10^{-4}$ & 86 & 5,6 \\
\hline $\mathrm{ZnO}: \mathrm{Al}$ & AZO-95 & 295 & 33,9 & $1,0 \times 10^{-3}$ & 87 & 7,3 \\
\hline $\mathrm{In}_{2} \mathrm{O}_{3}$ & IO-40 & 134 & 25,3 & $3,4 \times 10^{-4}$ & 92 & 17,2 \\
\hline $\mathrm{In}_{2} \mathrm{O}_{3}$ & IO-55 & 161 & 20,6 & $3,3 \times 10^{-4}$ & 91 & 18,9 \\
\hline $\mathrm{In}_{2} \mathrm{O}_{3}$ & IO-75 & 166 & 24,1 & $4,0 \times 10^{-4}$ & 91 & 16,2 \\
\hline $\mathrm{In}_{2} \mathrm{O}_{3}: \mathrm{Sn}$ & ITO-50 & 160 & 35,3 & $5,6 \times 10^{-4}$ & 90 & 9,9 \\
\hline $\mathrm{In}_{2} \mathrm{O}_{3}: \mathrm{Sn}$ & ITO-60 & 168 & 24,1 & $4,0 \times 10^{-4}$ & 91 & 16,2 \\
\hline $\mathrm{Cd}_{2} \mathrm{SnO}_{4}$ & CTO-45 & 195 & 66,7 & $1,3 \times 10^{-3}$ & 86 & 3,3 \\
\hline $\mathrm{Cd}_{2} \mathrm{SnO}_{4}$ & CTO-60 & 218 & 42,7 & $9,3 \times 10^{-4}$ & 84 & 4,1 \\
\hline $\mathrm{Zn}_{2} \mathrm{SnO}_{4}$ & ZTO-60 & 150 & $61 \times 10^{3}$ & $9,1 \times 10^{-1}$ & 92 & 0,007 \\
\hline $\mathrm{Zn}_{2} \mathrm{SnO}_{4}$ & ZTO-80 & 177 & $118 \times 10^{3}$ & 2,1 & 91 & 0,003 \\
\hline $\mathrm{Zn}_{2} \mathrm{SnO}_{4}$ & ZTO-100 & 179 & $31 \times 10^{3}$ & $5,6 \times 10^{-1}$ & 91 & 0,012 \\
\hline $\mathrm{ZnO}$ & $\mathrm{ZO-95}$ & 157 & $>10^{6}$ & $>16$ & 92 & $<0,0004$ \\
\hline
\end{tabular}

Levando-se em consideração questões de custo e escassez associadas ao índio, é interessante explorar as possibilidades de uso do $\mathrm{ZnO}$ :Al. Uma alternativa para reduzir a resistência obtida dos filmes de $\mathrm{ZnO}: \mathrm{Al}$ é aumentar sua espessura. A Tabela 4 mostra as características elétricas e óticas de filmes de $\mathrm{ZnO}$ :Al com várias espessuras (os valores de $\mathrm{T}$ referem-se à transmitância média do filme na faixa da radiação visível entre $450 \mathrm{~nm}-800 \mathrm{~nm}$, já excluída a parcela do substrato). Nota-se que a transmitância dos filmes não foi comprometida na faixa de espessura investigada. Por isso, o filme mais espesso, com a menor resistência de folha, é o que possui a maior figura de mérito.

O comportamento da transmitância dos filmes listados na Tabela 4 pode ser observado nos respectivos espectros da Figura 2. As oscilações observadas nos espectros devem-se às interferências construtivas e destrutivas na interface filme-substrato e estão de acordo com a relação entre as espessuras dos filmes (filmes mais espessos geram maior número de oscilações). Na região de absorção fundamental, observam-se variações na aresta de absorção em função da espessura, o que indica que a banda proibida dos filmes, que é obtida desta região, variou levemente com a espessura. A Figura 3 mostra as propriedades elétricas dos filmes de $\mathrm{ZnO}: \mathrm{Al}$ em função da espessura. Interessante destacar que a menor resistência, a qual foi obtida no filme mais espesso, deve-se aos maiores valores de mobilidade $(\mu)$ e concentração de portadores livres $(n)$ obtidos nesta amostra.

Os filmes de $\mathrm{ZnO}: \mathrm{Al}$ mais espessos foram então submetidos a testes adicionais de estabilidade térmica, em condições semelhantes às de crescimento da célula solar com configuração vidro/OTC-b/OTCa/CdS/CdTe. Para OTC-b e OTC-a foram utilizados, respectivamente, filmes de $\mathrm{ZnO}$ com $100 \mathrm{~nm}$ e filmes de $\mathrm{ZnO}$ :Al com 750nm ou $900 \mathrm{~nm}$. Assim, os eletrodos frontais vidro/ZnO/ZnO:Al foram submetidos às seguintes condições: pressão residual de argônio $=2 \mathrm{Torr}$; temperatura $=450-650^{\circ} \mathrm{C}$. Os resultados são mostrados na Figura 4, que faz uma comparação entre as variações de resistência dos vários eletrodos de OTCs submetidos aos testes. Observa-se que a resistência de folha do eletrodo vidro/ $\mathrm{ZnO} / \mathrm{ZnO}$ :Al variou muito pouco após o teste, o que mostra que filmes de $\mathrm{ZnO}$ e $\mathrm{ZnO}$ :Al são termicamente estáveis. 
Tabela 4: Propriedades elétricas e óticas de filmes de $\mathrm{ZnO}$ :Al com diferentes espessuras depositados sobre vidro, à temperatura ambiente, por pulverização catódica com rádio frequência.

\begin{tabular}{l|l|l|l|l}
\hline $\mathbf{D}(\mathbf{n m})$ & $\mathbf{R s}(\boldsymbol{\Omega} / \mathbf{q d})$ & $\boldsymbol{\rho}(\mathbf{\Omega . c m})$ & $\mathbf{T}(\%)$ & $\mathbf{\Phi}\left(\mathbf{1 0 ^ { - 3 }} \mathbf{\Omega}^{-\mathbf{1}}\right)$ \\
\hline 295 & 33,9 & $1,0 \times 10^{-3}$ & 87 & 7,3 \\
\hline 425 & 26,1 & $1,1 \times 10^{-3}$ & 86 & 8,5 \\
\hline 610 & 12,0 & $7,3 \times 10^{-4}$ & 86 & 18,4 \\
\hline 810 & 7,0 & $5,7 \times 10^{-4}$ & 84 & 24,9 \\
\hline
\end{tabular}

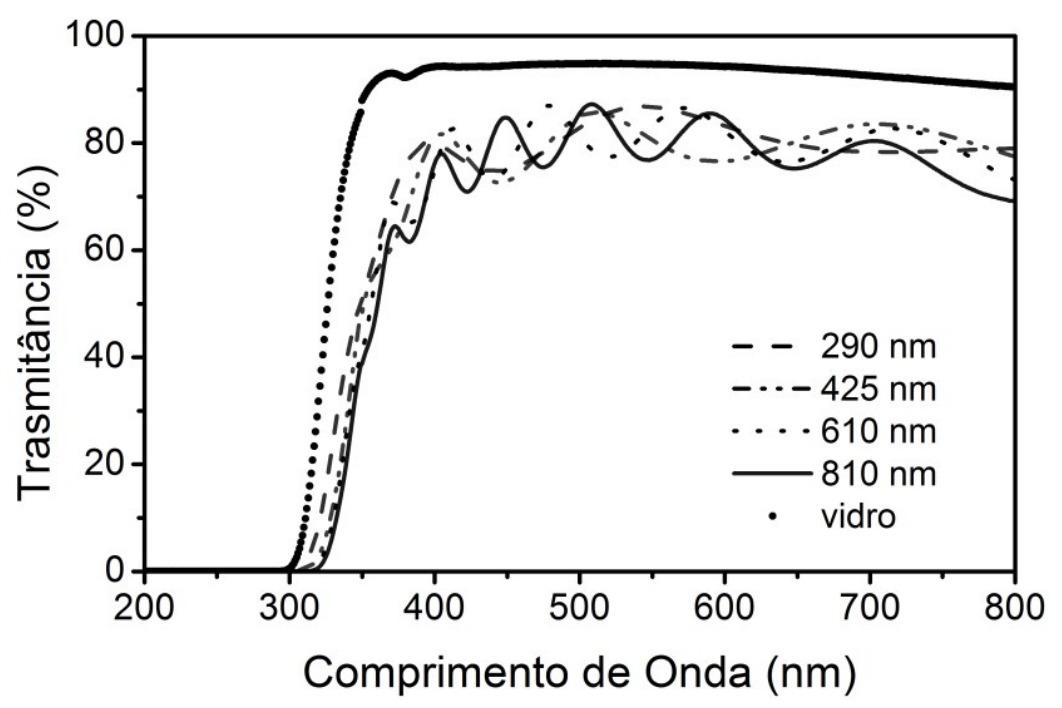

Figura 2: Espectros de transmitância de filmes de $\mathrm{ZnO}: \mathrm{Al}$ com diferentes espessuras depositados sobre vidro, à temperatura ambiente, por pulverização catódica com rádio frequência.

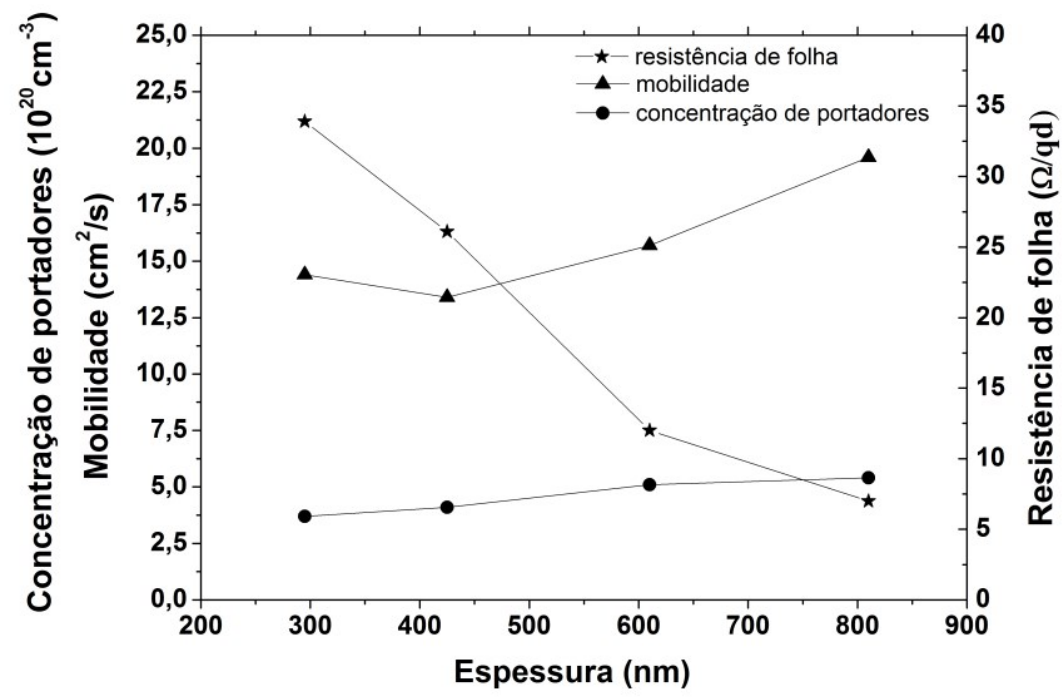

Figura 3: Propriedades elétricas de filmes de $\mathrm{ZnO}: \mathrm{Al}$ com diferentes espessuras depositados sobre vidro, à temperatura ambiente, por pulverização catódica com rádio frequência. 


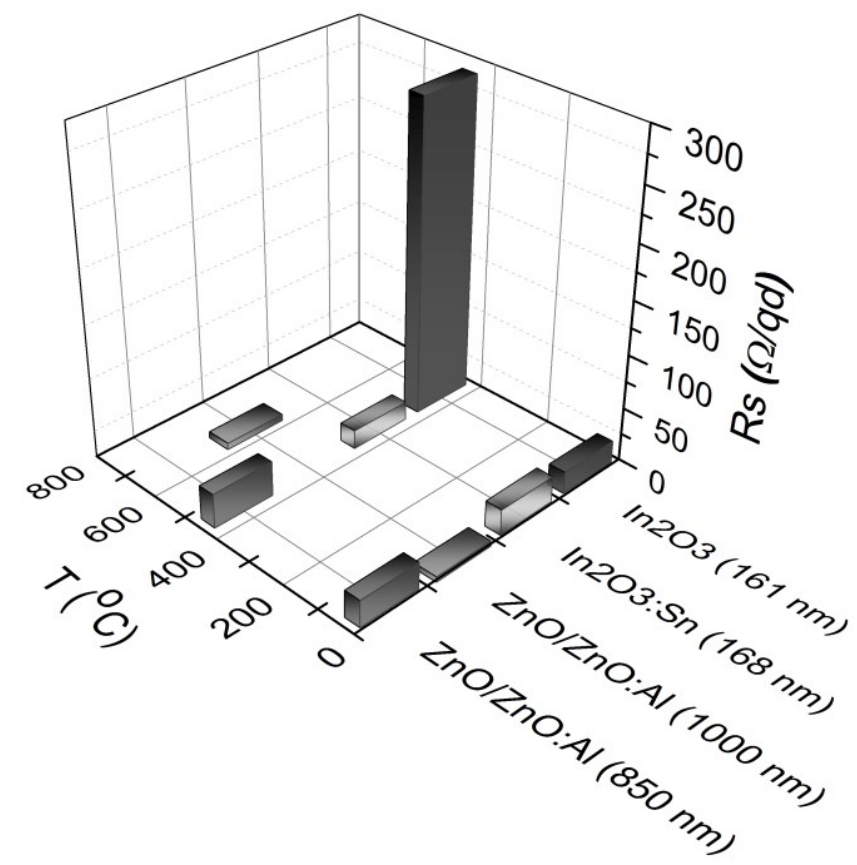

Figura 4: Resistência de folha de vários eletrodos frontais vidro/OTC para células solares de CdTe, antes e depois de serem submetidos a temperaturas elevadas por $15 \mathrm{~min}$.

A Tabela 5 mostra as propriedades elétricas dos eletrodos de vidro/ZnO/ZnO:Al, mostrados na Figura 4, antes e após serem expostos ao teste de estabilidade. Os resultados mostram que o pequeno aumento observado na resistência deveu-se ao decréscimo da concentração de portadores livres (n), provavelmente ocasionado pela redução na densidade de vacâncias de oxigênio após exposição do filme a temperaturas elevadas.

Assim, pode-se concluir que, dentre os filmes estudados, os de $\mathrm{ZnO}$ :Al são os mais indicados para serem utilizados como contatos frontais em células solares de CdTe, por apresentarem valores de resistência e transmitância adequados a esta aplicação, além de demonstrarem elevada estabilidade térmica nas temperaturas de processamento da célula.

Tabela 5: Propriedades elétricas "vidro/ZnO:Al/ZnO” para células solares de CdTe, antes e depois de serem submetidos a temperaturas elevadas por $15 \mathrm{~min}$.

\begin{tabular}{l|l|l|l|l|l}
\hline AMOSTRA & Temperatura $\left({ }^{\circ} \mathbf{C}\right)$ & Rs $(\Omega / \mathbf{q d})$ & $\boldsymbol{\mu}\left(\mathbf{c m}^{\mathbf{2}} / \mathbf{V} . \mathbf{s}\right)$ & $\mathbf{n}\left(\mathbf{1 0 ^ { 2 0 }} \mathbf{c m}^{-\mathbf{3}}\right)$ & $\boldsymbol{\rho}(\mathbf{\Omega . c m})$ \\
\hline vidro/ZnO:Al$(750 \mathrm{~nm}) / \mathrm{ZnO}(100 \mathrm{~nm})$ & 25 & 25 & 10,1 & 3,0 & $2,0 \times 10^{-3}$ \\
\hline vidro/ZnO:Al(750nm)/ZnO(100nm) & 450 & 32 & 9,3 & 2,5 & $2,5 \times 10^{-3}$ \\
\hline vidro/ZnO:Al $(900 \mathrm{~nm}) / \mathrm{ZnO}(100 \mathrm{~nm})$ & 25 & 5 & 12,8 & 9,4 & $5,1 \times 10^{-4}$ \\
\hline vidro/ZnO:Al(900nm)/ZnO(100nm) & 650 & 6 & 19,9 & 6,1 & $6,0 \times 10^{-4}$ \\
\hline
\end{tabular}

\section{CONCLUSÕES}

A técnica de pulverização catódica à temperatura ambiente permite a obtenção de filmes de OTCs com excelentes propriedades condutoras e de transmitância, similares às de filmes que são submetidos a tratamento térmico posterior. Levando-se em consideração questões de custo e escassez de matéria prima, pode-se concluir que, dentre os materiais investigados, os filmes de $\mathrm{ZnO}$ :Al são a melhor alternativa para fabricação dos eletrodos frontais das células solares de filmes finos, por apresentarem valores de resistência e transmitância adequados a esta aplicação, além de demonstrarem elevada estabilidade térmica nas temperaturas de processamento da célula.

\section{AGRADECIMENTOS}

Este trabalho foi financiado pelo CNPq, projeto 555710/2010-6, e pelos Programas PIBITI/CNPq e DS/CAPES. 


\section{BIBLIOGRAFIA}

[1] LEWIS, B.G., PAINE, D.C., “Applications and processing of transparent conducting oxides”, MRS Bulletin, vol. 25, pp. 22-27, 2000.

[2] TAGUCHI, M.,TERAKAWA, A., MARUYAMA, E., et al., "Obtaining a Higher Voc in HIT Cells", Progress in Photovoltaics: Res. Appl., v. 13, pp. 481-488, 2005.

[3] KAZMERSKI, L.L., "Solar photovoltaics R\&D at the tipping point: A 2005 technology overview”, J. of Electron Spectroscopy and Related Phenomena, v. 150, pp. 105-135, 2006.

[4] ROMEO, N., BOSIO, A., CANEVARI, V., TERHEGGEN, M., et al., "Comparison of different conducting oxides as substrates for CdS/CdTe thin film solar cells”, Thin Solid Films, v. 431-432, pp. 364-368, 2003.

[5] JEYADHEEPAN, K., THAMILSELVAN, M., KIM, K., et al., "Optoelectronic properties of RF magnetron sputtered cadmium tin oxide $\left(\mathrm{Cd}_{2} \mathrm{SnO}_{4}\right)$ thin films for $\mathrm{CdS} / \mathrm{CdTe}$ thin film solar cell applications", J. of Alloys and Compounds, v. 620, pp. 185-191, 2015.

[6] BOSIO, A., ROMEO, N., MAZZAMUTO, S., et al., "Polycrystalline CdTe thin films for photovoltaic applications", Progress in Crystal Growth and Characterization of Materials, v. 52, pp. 247-279, 2006.

[7] FEREKIDES, C.S., MAMAZZA, R., BALASUBRAMANIAN, U., et al., "Transparent conductors and buffer layers for CdTe solar cells", Thin Solid Films, v. 480-481, pp. 224-229, 2005.

[8] CHOPRA, K.L., PAULSON, P.D., DUTRA, E.V., “Thin-Film solar cells: an overview”, Progress in Photovoltaics: Research and Applications, v. 12, pp. 69-92, 2004.

[9] WU, X., "High-efficiency polycrystalline CdTe thin-film solar cells", Solar Energy, v. 77, n. 6, pp. 803814, 2004.

[10] KAUR, G., MITRA, A., YADAV, K.L., "Pulsed laser deposited Al-doped ZnO thin films for optical applications", Progress in Natural Science: Materials International, v. 25, pp. 12-21, 2015.

[11] DING, J.N., TAN, C.B., YUAN, N.Y., et al., "The preparation and properties of Al-doped ZnO thin films as transparent electrodes for solar cell", Physics Procedia, v. 32, pp. 789-794, 2012.

[12] JEONG, W.J., KIM, S.K., PARK, G.C., "Preparation and characteristic of ZnO thin film with high and low resistivity for an application of solar cell”, Thin Solid Films, v. 506, pp. 180-183, 2006.

[13] GUILLÉN, C., HERRERO, J., "Optical, electrical and structural characteristics of Al:ZnO thin films with various thicknesses deposited by DC sputtering at room temperature and annealed in air or vacuum", Vacuum, v. 84, n. 7, pp. 924-929, 2010.

[14] DIAS, C.A.C.M., PAES JÚNIOR, H.R., "Produção e Caracterização de Filmes Finos de Óxido de Zinco Intrínsecos e Dopados com Alumínio e Boro”, Revista Matéria, v. 11, n. 3, pp. 267-272, 2006.

[15] FALCÃO, V.D., MIRANDA, D.O., SABINO, M.E.L., et al., "Comparative study of ZnO thin films prepared by plasma deposition and electron beam evaporation for use in photovoltaic devices", Progress in Photovoltaics: Res. Appl., v. 19, pp. 149-154, 2011.

[16] MACIEL JR, J.L.B., SCALVI, L.V.A., "Efeitos da temperatura de deposição nas propriedades óticas e elétricas de filmes finos de $\mathrm{SnO}_{2}$ obtidos via sol-gel”, Revista Brasileira de Aplicações de Vácuo, v. 25, n. 4, pp. 197-201, 2006.

[17] HAACKE, G., "New figure of merit for transparent conductors", Journal of Applied Physics, v. 47, pp. 4086-4089, 1976.

[18] MEDEIRO, R.A., Produção de multicamadas de filmes finos de VOx por pulverização catódica sem quebra de vácuo, Tese de D.Sc., IME, Rio de Janeiro, RJ, Brasil, 2015. 